\title{
Pre-cachexia and cachexia at diagnosis of stage III non-small-cell lung carcinoma: an exploratory study comparing two consensus-based frameworks
}

\author{
Barbara S. van der Meij ${ }^{1 *}$, Coline P. Schoonbeek ${ }^{1}$, Egbert F. Smit ${ }^{2}$, Maurizio Muscaritoli ${ }^{3}$, \\ Paul A. M. van Leeuwen ${ }^{4}$ and Jacqueline A. E. Langius ${ }^{1}$ \\ ${ }^{1}$ Department of Nutrition and Dietetics, Internal Medicine, VU University Medical Center, \\ PO Box 7057, 1007 MB, Amsterdam, The Netherlands \\ ${ }^{2}$ Department of Pulmonary Diseases, VU University Medical Center, Amsterdam, The Netherlands \\ ${ }^{3}$ Department of Clinical Medicine - Sapienza, University of Rome, Rome, Italy \\ ${ }^{4}$ Department of Surgery, VU University Medical Center, Amsterdam, The Netherlands \\ (Submitted 11 April 2012 - Final revision received 25 July 2012 - Accepted 21 August 2012 - First published online 16 November 2012)
}

\section{Abstract}

Despite the development of consensus-based frameworks to define cancer cachexia, the validity and usefulness of these frameworks are relatively unknown. The aim of the present study was to study the presence of pre-cachexia and cachexia in patients with stage III nonsmall-cell lung carcinoma (NSCLC) by using a cancer-specific framework and a general framework for cachexia, and to explore the prognostic value of pre-cachexia and cachexia. In forty patients at diagnosis of stage III NSCLC, weight loss, fat-free mass, handgrip strength, anorexia and serum biochemistry, assessed before the first chemotherapy, were used to define 'cancer cachexia' or 'cachexia'. The cancerspecific framework also classified for pre-cachexia and refractory cachexia. Additionally, quality of life was assessed by the European Organisation for Research and Treatment of Cancer - Quality of Life Questionnaire C30. Groups were compared using independent $t$ tests, ANOVA, Kaplan-Meier and Cox survival analyses. Based on the cancer-specific framework, pre-cachexia was present in nine patients (23\%) and cancer cachexia was present in seven patients (18\%). Cancer cachexia was associated with a reduced quality of life $(P=0 \cdot 03)$ and shorter survival (hazard ratio $(\mathrm{HR})=2 \cdot 9 ; P=0.04)$. When using the general framework, cachexia was present in eleven patients $(28 \%)$, and was associated with a reduced quality of life $(P=0 \cdot 08)$ and shorter survival $(\mathrm{HR}=4 \cdot 4 ; P=0 \cdot 001)$. In conclusion, pre-cachexia and cachexia are prevalent in this small population of patients at diagnosis of stage III NSCLC. For both frameworks, cachexia appears to be associated with a reduced quality of life and shorter survival. Further studies are warranted to more extensively explore the validity and prognostic value of these new frameworks in cancer patients.

\section{Key words: Pre-cachexia: Cachexia: Non-small-cell lung cancer}

Cachexia is a complex metabolic syndrome characterised by ongoing loss of body weight and skeletal muscle mass, which cannot be fully reversed by conventional nutritional support ${ }^{(1)}$. The pathophysiology of cachexia encompasses a negative protein and energy balance, driven by a variable combination of reduced food intake and abnormal metabolism. Cachexia is frequently observed in patients with cancer, and is associated with progressive functional impairment, intolerance to anticancer treatment and shorter survival ${ }^{(1-3)}$.

The severity of cachexia in patients with cancer varies from non-symptomatic inflammatory derangements and minimal weight and muscle loss in the early stage to severe muscle wasting and low performance status in patients not responding to anticancer treatment ${ }^{(4)}$

In order to define and stage cachexia, a number of frameworks in patients with chronic diseases ${ }^{(1,5)}$ and cancer ${ }^{(4,6-8)}$ have been described. Recently, an international expert group proposed a conceptual framework for cancer cachexia, with a classification for three stages of clinical relevance: pre-cachexia, cachexia and refractory cachexia ${ }^{(4)}$. Overall, existing instruments use slightly different nutritional and inflammatory parameters and cut-off points to define pre-cachexia and cachexia.

Despite the growing understanding of the pathophysiology and staging of cachexia, assessment of cachexia in clinical

Abbreviations: CRP, C-reactive protein; EORTC-QLQC30, European Organisation for Research and Treatment of Cancer - Quality of Life Questionnaire C30; ESPEN, European Society for Parenteral and Enteral Nutrition; FFM, fat-free mass; HR, hazard ratio; NSCLC, non-small-cell lung cancer; REE, resting energy expenditure; TEE, total energy expenditure; VAS, visual analogue scale.

*Corresponding author: B. S. van der Meij, fax +31 20444 4143, email b.vandermeij@vumc.nl 
practice is limited. These studies clearly showed the occurrence of weight loss and features of cachexia in patients with cancer.

In patients with lung cancer, high prevalences of involuntary weight loss have been reported ${ }^{(9-11)}$. Lung cancer is frequently associated with cachexia. Weight loss in patients with lung cancer was associated with systemic inflammation, loss of muscle mass, an increased acute-phase response, decreased levels of the anabolic hormone insulin-like growth factor- $\mathrm{I}^{(12)}$ and hypermetabolism ${ }^{(12,13)}$. Weight loss was also associated with reduced quality of life ${ }^{(14)}$, response to chemotherapy ${ }^{(15)}$ and survival ${ }^{(9,16)}$ in patients with lung cancer.

The staging of cachexia in patients with lung cancer has not been described, but could help clinicians to decide on early interventions or cachexia treatment. Up to now, the validity and usefulness of cachexia instruments in patients with cancer is unknown, and the recognition and nutritional management of cancer cachexia remains unsatisfactory ${ }^{(1)}$.

Comprehensive data of cancer populations could give more insight into the pathophysiology of (pre)cachexia, and could be used to apply cachexia frameworks and to investigate the outcomes and differences between frameworks. Therefore, we aimed to retrospectively study the presence of (pre) cachexia at diagnosis of stage III non-small-cell lung cancer (NSCLC), using recently described consensus-based frameworks $^{(1,4,5)}$, and to explore the prognostic value of precachexia and cachexia. Second, we explored quality of life, and nutritional and inflammatory parameters associated with (pre)cachexia. We hypothesise that (pre)cachexia is present in this locally advanced patient population and that cachexia is associated with a decreased quality of life and shorter survival.

\section{Materials and methods}

\section{Patients}

Between March 2005 and October 2007, forty patients with histologically or cytologically proven stage III NSCLC, aged 18-80 years and having a life expectancy of at least 3 months, were included at the start of concurrent chemoradiotherapy. Patients were excluded if they had undergone surgery, chemotherapy or radiotherapy during the previous month; if they had oedema, ascites or severe co-morbidities; or if they used high-dose corticosteroids or fish oil supplements.

Data used for the present retrospective analysis were collected at the inclusion for a prospective double-blind randomised controlled trial that has been carried out at our centre from 2005 to 2008. Out of fifty-five enrolled patients, four patients did not meet the inclusion criteria, nine patients refused to participate and two had disease progression (Fig. S1, available online). We used the baseline and survival data of forty patients, irrespective of the intervention in the trial. After carrying out baseline measurements, patients were randomly assigned to receive two cans per $\mathrm{d}$ of either a protein- and energy-dense oral nutritional supplement containing $n-3$ PUFA or an isoenergetic control oral nutritional supplement during 5 weeks of chemoradiotherapy ${ }^{(17)}$.
Throughout chemoradiotherapy, the dietitian monitored dietary intake and provided dietary counselling. Tube feeding was indicated in the case of an (expected) oral intake of $<75 \%$ of energy requirements for more than $3 \mathrm{~d}$, combined with the inability to increase energy intake by oral food or sip feeds.

The present study was conducted according to the guidelines laid down in the Declaration of Helsinki, and all procedures involving human patients were approved by the Medical Ethics Committee of the VU University Medical Center, Amsterdam, The Netherlands. Written informed consent was obtained from all patients.

\section{Baseline measurements}

At baseline, before the start of chemoradiotherapy, weight loss, BMI, fat-free mass (FFM), energy expenditure, anorexia, inflammation, muscle strength, quality of life and physical activity were assessed.

\section{Weight loss and BMI}

Pre-illness weight, unintentional weight loss in the last month and during the last 6 months and height were recorded. Body weight, without shoes and wearing light clothing, was measured on a compact digital flat scale (SECA 888) to the nearest $0.2 \mathrm{~kg}$. BMI was calculated by dividing body weight $(\mathrm{kg})$ by the square of the height $(\mathrm{m})$.

\section{Fat-free mass}

Bioelectrical impedance spectroscopy (Hydra 4200, Xitron Technologies) was performed to assess FFM. Whole-body resistance was measured with four surface electrodes placed on the right wrist and ankle, as previously described ${ }^{(18)}$. Briefly, the principle was based on the application of a variable electrical current between 50 and $700 \mu \mathrm{A}$ produced by a generator and applied to the skin using adhesive electrodes (3M red Dot $\mathrm{Ag} / \mathrm{AgCl}$ ) with the subject lying supine ${ }^{(19)}$. FFM was calculated from resistance and reactance at the frequency of capacitance by using the Kyle Geneva equation ${ }^{(20)}$.

The phase angle of bioelectrical impedance at $50 \mathrm{kHz}$ was calculated using the following equation: phase angle $=$ (resistance/reactance) $\times(180 / \pi)$. The cut-off point for patients with lung cancer, described by Gupta et $a l .{ }^{(21)}$, was used to classify patients with a low $(\leq 5 \cdot 3)$ and high $(>5.3)$ phase angle.

\section{Energy expenditure}

Resting energy expenditure (REE) was measured by a ventilated hood system (Deltatrac, Datex); $\mathrm{CO}_{2}$ production $\left(\mathrm{VCO}_{2}\right)$ and $\mathrm{O}_{2}$ consumption $\left(\mathrm{VO}_{2}\right)$ were measured at complete rest for a period of $30 \mathrm{~min}$. REE was calculated using a modified Weir equation ${ }^{(22,23)}$. To estimate total energy expenditure (TEE), 30\% was added to REE, assuming a physical activity level of 1.3 for sedentary patients with cancer ${ }^{(24)}$. 


\section{Anorexia}

Patients recorded their appetite on a visual analogue scale (VAS), $10 \mathrm{~cm}$ in length ${ }^{(25)}$. Patients' energy intake, assessed by a $24 \mathrm{~h}$ dietary recall, was expressed as percentage of TEE. Anorexia and/or reduced food intake were identified by the presence of appetite $<5 \mathrm{~cm}$ (VAS), energy intake $<84 \mathrm{~kJ} / \mathrm{kg}$ body weight per $\mathrm{d}(84 \mathrm{~kJ}(20 \mathrm{kcal}) / \mathrm{kg})^{(11)}$ or energy intake $<70 \%$ of $\mathrm{TEE}^{(1)}$.

Inflammation. Non-fasting blood samples were taken simultaneously with usual blood samples for chemotherapy. Plasma concentrations of C-reactive protein (CRP) were measured with an automated latex-enhanced immunoturbidimetric assay on a Modular P analyser (reference: $0-8 \mathrm{mg} / \mathrm{l}{ }^{(26)}$. Serum IL-6 was measured by commercially available ELISA (Pelikine compact human ELISA kits, Sanquin) (reference: 0-4 pg/ml). Whole-blood $\mathrm{Hb}$ was determined by spectrophotometry on a Cell-Dyn Sapphire analyser (Abbott Diagnostics) (reference: $\geq 7.3 \mathrm{mmol} / 1$ or $\geq 117 \mathrm{~g} /)^{(27)}$. Serum albumin concentrations were chemically determined on a Modular $\mathrm{P}$ analyser (ACN 760, 11815148 216, Roche Diagnostics) (reference: $\geq 320 \mathrm{~g} / 1)^{(28)}$.

Muscle strength. Muscle strength was measured by handgrip strength in the non-dominant hand using a hydraulic hand dynamometer (Baseline, Fabrication Enterprises). The patient performed two maximal isometric contractions while sitting, with the shoulder adducted and neutrally rotated, elbow flexed at $90^{\circ}$ and the forearm and wrist in neutral position. The average of two measurements was recorded, and compared with age- and sex-dependent reference values for handgrip strength ${ }^{(29)}$.

Additional parameters. We assessed additional parameters that could be related to cancer cachexia, such as quality of life, physical activity level and survival.

The investigator recorded the Karnofsky Performance Score, a valid and widely used instrument to quantify the functional status of cancer patients. The Karnofsky Performance Score ranges from 0 to 100 , with a higher score indicating a better ability to carry out normal daily activities and work ${ }^{(30,31)}$.

Patients filled out the European Organisation for Research and Treatment of Cancer - Quality of Life Questionnaire C30 (EORTC-QLQC30) questionnaire, a multidimensional validated cancer-specific measure that includes global health status, physical status, functional and symptom scales (i.e. fatigue) $^{(12,17,18)}$.

Physical activity was assessed by the Physical Activity Monitor accelerometer. Patients were instructed to wear the Physical Activity Monitor for seven consecutive days on the hip (model AM101, 28g, $59 \times 43 \times 10 \mathrm{~mm}$, PAM B.V.) ${ }^{(32)}$. The Physical Activity Monitor produces a single index score, which is a proxy measure of total daily physical activity. Every three points of the physical activity score reflects about $10 \mathrm{~min}$ walking. The Physical Activity Monitor also produces minutes of low- and moderate-intensity activities; low-intensity physical activity corresponds with small in-house movements and moderate-intensity activity corresponds with walking ${ }^{(33)}$.

\section{Definition of pre-cachexia and cachexia}

We used two consensus-based frameworks to define cachexia: a cancer-specific and a non-disease-specific general framework. With the cancer-specific framework, we defined pre-cachexia, cancer cachexia and refractory cancer cachexia, as proposed by, respectively, the European Society for Parenteral and Enteral Nutrition (ESPEN) Special Interest Group 'cachexia-anorexia in chronic wasting diseases'(1) and an international panel of experts in clinical cancer cachexia research ${ }^{(4)}$. Second, we used the general framework for cachexia in chronic illness, as described by Evans et al. ${ }^{(5)}$. Some of the parameters and cut-off points not specifically given a reference citation in the sections below were not described in frameworks, and therefore retrieved from available unspecified literature and, where necessary, from experts.

\section{Cancer-specific framework for cachexia}

Cancer pre-cachexia ${ }^{(1)}$ :

(1) Unintentional weight loss of 0 to $\leq 5 \%$ during the previous 6 months.

(2) Anorexia (the presence of either: appetite $<5 \mathrm{~cm}$ (VAS), energy intake $<84 \mathrm{~kJ} / \mathrm{kg}$ body weight per d $(84 \mathrm{~kJ}$ $(20 \mathrm{kcal}) / \mathrm{kg})^{(11)}$ or energy intake $<70 \%$ of $\left.\mathrm{TEE}^{(1)}\right)$.

(3) Systemic inflammation (CRP $\geq 8 \mathrm{mg} / \mathrm{l}$, the upper limit of normality).

Cancer cachexia $^{(4)}$ :

(1) Weight loss $>5 \%$ during the previous 6 months or BMI $<20 \mathrm{~kg} / \mathrm{m}^{2}$ and weight loss $>2 \%$ or sarcopenia (FFM index $<5$ th percentile of age- and sex-specific reference values $^{(34)}$ and weight loss $>2 \%$ ).

(2) Reduced food intake (the presence of either: appetite $<5 \mathrm{~cm}$ (VAS), energy intake $<84 \mathrm{~kJ} / \mathrm{kg}$ body weight per $\mathrm{d}$ $(84 \mathrm{~kJ}(20 \mathrm{kcal}) / \mathrm{kg})^{(11)}$ or energy intake $<70 \%$ of $\left.\mathrm{TEE}^{(1)}\right)$.

(3) Systemic inflammation ( $\mathrm{CRP} \geq 8 \mathrm{mg} / \mathrm{l}$, the upper limit of normality)

Refractory cancer cachexia ${ }^{(4)}$ :

(1) Variable degree of 'cancer cachexia'.

(2) Cancer disease both pro-catabolic and not responsive to anticancer treatment.

(3) Low performance score (Karnofsky Performance Score $<50$, indicating that a patient is unable to care for self).

(4) $<3$ months expected survival.

\section{General framework}

The non-disease-specific general framework for cachexia ${ }^{(5)}$ includes the combination of weight loss of $\geq 5 \%$ in 6 months or BMI $<20 \mathrm{~kg} / \mathrm{m}^{2}$, combined with at least three of the following five criteria:

(1) Decreased muscle strength.

Handgrip strength below the lowest tertile extracted from age- and sex-specific reference values ${ }^{(29)}$. 
(2) Fatigue (score of 3 or 4 according to the EORTC-QLQC30 symptom scale $\left.{ }^{(12)}\right)$.

(3) Anorexia (the presence of: appetite $<5 \mathrm{~cm}$ (VAS), energy intake $<84 \mathrm{~kJ} / \mathrm{kg}$ body weight per d $(84 \mathrm{~kJ}(20 \mathrm{kcal}) /$ $\mathrm{kg})^{(11)}$ or energy intake $<70 \%$ of $\left.\mathrm{TEE}^{(1)}\right)$.

(4) FFM index below the 10th percentile by age- and sexspecific reference values ${ }^{(13)}$

(5) One or more abnormal serum biochemistry parameters: $\mathrm{CRP}>5 \mathrm{mg} / 1, \mathrm{Hb}<120 \mathrm{~g} / 1$ or $117 \mathrm{~g} / 1$, serum albumin $<320 \mathrm{~g} / \mathrm{l}$ or IL- $6>4 \mathrm{pg} / \mathrm{ml}^{(6)}$.

\section{Statistical analysis}

Statistical analysis was performed using SPSS for Windows (version 17.0, SPSS, Inc.). Groups with no cachexia, pre-cachexia and cachexia were compared for serum biochemistry, REE, quality of life and physical role, emotional, cognitive and social functioning. Independent samples $t$ tests were performed to compare groups with no cachexia and cachexia. For variables that were not normally distributed, non-parametric tests were performed to compare group differences. Frequencies within groups for nominal characteristics were compared by Pearson's $\chi^{2}$ tests. Differences between three groups (no cachexia, pre-cachexia and cachexia) were tested by one-way ANOVA. Correlations between variables were investigated by Pearson's correlation tests.

Group survival, from the date of the start of concurrent chemoradiotherapy (from 15 March 2005 until 30 October 2007) until death or follow-up visit (17 November 2011), was generated by the method of Kaplan and Meier and compared by means of the log-rank test. Second, the multivariate Cox's regression proportional hazards model was used to analyse hazard ratios (HR) for survival. Cachexia was the independent variable, and the model was adjusted for confounding factor(s) (based on a $>10 \%$ change of $\mathrm{OR}$, after adding a single factor: sex, age and/or tumour stage: IIIa $v$. IIIb). Median survival was displayed with the standard error; $P$ values $<0.05$ were considered to be statistically significant.

\section{Results}

\section{Patients}

A total of forty patients with histologically or cytologically proven stage IIIa ( $n$ 16) or stage IIIb ( $n$ 24) NSCLC were studied, nineteen females and twenty-one males, with a median age of 57 (range 39-80) years. The average amount of weight loss during the previous 6 months was 1.9 (SD 6.5) \% of pre-illness weight. The overall median survival was $25 \cdot 0$ (SD $8 \cdot 7$ ) months. Baseline patient characteristics are displayed in Table 1.

\section{Cancer-specific framework}

Using the two consensus-based frameworks of the ESPEN Special Interest Group ${ }^{(1)}$ and Fearon et $a l^{(4)}$, we classified pre-cachexia in nine patients (23\%) and cachexia in seven patients (18\%). The remaining twenty-four patients were classified as no-cachexia patients (Table 2). None of the patients met the criteria of refractory cancer cachexia: measurements were carried out at diagnosis, just before starting anticancer treatment, and the Karnofsky performance score was relatively high (70-100) and the expected survival was at least 3 months in all patients.

Quality of life was significantly different among no-cachexia, pre-cachexia and cachexia groups $(P=0 \cdot 03)$, but other function scales (such as physical function) did not significantly differ between groups. Survival was non-significantly different between no-cachexia, pre-cachexia and cachexia groups in univariate analysis (24 (SD 11.6) v. 32 (SD 1.5) v. 9 (SD 9.2) months,

Table 1. Baseline characteristics for patients with stage III non-small-cell lung cancer, specified for groups with no cachexia, pre-cachexia and cachexia, as defined by different consensus-based frameworks

(Mean values and standard deviations; number of participants and percentages)

\begin{tabular}{|c|c|c|c|c|c|c|c|c|c|c|c|c|c|c|}
\hline & & & \multicolumn{7}{|c|}{ Cancer } & \multicolumn{5}{|c|}{ General } \\
\hline & \multicolumn{2}{|c|}{$\begin{array}{l}\text { Overall } \\
(n 40)\end{array}$} & \multicolumn{2}{|c|}{$\begin{array}{l}\text { No cachexia } \\
\quad(n 24)\end{array}$} & \multicolumn{2}{|c|}{$\begin{array}{c}\text { Pre- } \\
\text { cachexia } \\
(n 9)\end{array}$} & \multicolumn{2}{|c|}{$\begin{array}{l}\text { Cachexia } \\
\quad(n 7)\end{array}$} & \multirow[b]{2}{*}{$P$} & \multicolumn{2}{|c|}{$\begin{array}{l}\text { No cachexia } \\
\quad(n 29)\end{array}$} & \multicolumn{2}{|c|}{$\begin{array}{l}\text { Cachexia } \\
\quad(n 11)\end{array}$} & \multirow[b]{2}{*}{$P$} \\
\hline & Mean & SD & Mean & SD & Mean & SD & Mean & SD & & Mean & SD & Mean & SD & \\
\hline $\begin{array}{l}\text { Age (years) } \\
\text { Female }\end{array}$ & $57 \cdot 8$ & $10 \cdot 1$ & $57 \cdot 7$ & $11 \cdot 1$ & $57 \cdot 0$ & $8 \cdot 1$ & $59 \cdot 0$ & $10 \cdot 0$ & $\begin{array}{l}0.93^{\star} \\
0.59 \ddagger\end{array}$ & $57 \cdot 4$ & 9.9 & $58 \cdot 6$ & $11 \cdot 2$ & $\begin{array}{l}0.75 \dagger \\
0.58 \ddagger\end{array}$ \\
\hline $\begin{array}{l}n \\
\%\end{array}$ & \multicolumn{2}{|c|}{47.5} & \multicolumn{2}{|c|}{12} & \multicolumn{2}{|c|}{3} & 57 & & & \multicolumn{2}{|c|}{13} & $\begin{array}{r}6 \\
5\end{array}$ & & \\
\hline $\begin{array}{l}\text { Tumour stage } \\
\text { Illa }\end{array}$ & & & & & & & & & $0.64 \ddagger$ & & & & & $0.77 \ddagger$ \\
\hline$n$ & \multicolumn{2}{|c|}{16} & \multicolumn{2}{|c|}{11} & 3 & & \multicolumn{2}{|l|}{2} & & 12 & & \multicolumn{2}{|c|}{4} & \\
\hline$\%$ & \multirow{2}{*}{\multicolumn{2}{|c|}{40}} & \multirow{2}{*}{\multicolumn{2}{|c|}{46}} & 33 & & \multirow{2}{*}{\multicolumn{2}{|c|}{29}} & & 4 & & \multirow{2}{*}{\multicolumn{2}{|c|}{36}} & \\
\hline Illb & & & & & & & & & & & & & & \\
\hline$n$ & \multirow{2}{*}{\multicolumn{2}{|c|}{$\begin{array}{l}24 \\
60\end{array}$}} & \multirow{2}{*}{\multicolumn{2}{|c|}{$\begin{array}{l}13 \\
54\end{array}$}} & 6 & & \multicolumn{2}{|c|}{5} & & 17 & & \multicolumn{2}{|c|}{7} & \\
\hline$\%$ & & & & & 67 & & 71 & & & $5 s$ & & 6 & & \\
\hline $\begin{array}{l}\text { Weight change in previous } \\
6 \text { months (\%) }\end{array}$ & $-1 \cdot 3$ & 4.5 & 0.3 & $5 \cdot 5$ & -0.5 & 1.0 & $-11 \cdot 6$ & $5 \cdot 0$ & $<0.001^{*}$ & 0.9 & $4 \cdot 3$ & -9.5 & $5 \cdot 2$ & $<0.001 \dagger$ \\
\hline BMI $\left(\mathrm{kg} / \mathrm{m}^{2}\right)$ & 23.9 & 3.5 & 24.5 & 3.5 & 23.5 & $2 \cdot 8$ & $22 \cdot 5$ & $4 \cdot 2$ & $0.36^{\star}$ & $24 \cdot 4$ & $3 \cdot 4$ & $22 \cdot 6$ & 3.5 & $0.14 \dagger$ \\
\hline
\end{tabular}

*ANOVA (comparing no-cachexia, pre-cachexia and cachexia groups).

$\dagger$ Independent samples $t$ test for equality of means (comparing no-cachexia and cachexia groups).

$\ddagger$ Pearson's $\chi^{2}$ test (comparing no-cachexia and (pre)cachexia groups). 
Table 2. Number of patients with stage III non-small-cell lung cancer classified as having no cachexia, pre-cachexia and cachexia

\begin{tabular}{lcccc}
\hline \multicolumn{4}{c}{ Cancer } \\
\cline { 2 - 5 } & No cachexia & Pre-cachexia & Cachexia & Total \\
\hline General & & & & \\
$\quad$ No cachexia & 20 & 9 & 0 & 29 \\
Cachexia & 4 & 0 & 7 & 11 \\
Total & 24 & 9 & 7 & 40 \\
\hline
\end{tabular}

respectively; $P=0 \cdot 21$ ) (Fig. 1 ). Multivariate analysis with no cachexia as the reference category, corrected for sex and tumour stage, showed a significantly shorter survival in patients with cancer cachexia (HR 2.93; 95\% CI 1.03, 8.34; P=0.04), but not in patients with pre-cachexia (HR $0 \cdot 78$; $95 \%$ CI 0.30, 2.03; $P=0.62)$.

\section{General framework}

Using the general framework to define cachexia, we identified eleven (28\%) out of forty patients with cachexia and twentynine patients (72\%) as having no cachexia (Table 2). The four patients who were classified as cachectic using the general definition, but not when using the cancer-specific framework, did not experience anorexia, but scored positive in at least three other features of the general definition (Table 3). Cachexia tended to be associated with a trend for a lower quality of life $(P=0 \cdot 08)$. Between the general no-cachexia and the cachexia groups, median survival was significantly different (respectively, 32.0 (SD 4.5) v. 10.0 (SD 3.7) months; $P<0.01$ ) (Fig. 2). In multivariate analysis, corrected for confounding by sex and tumour stage, cachexia remained significantly associated with a shorter survival (HR $4 \cdot 2 ; 95 \%$ CI $1 \cdot 7$, $10 \cdot 0 ; P=0 \cdot 001)$.

\section{Cachexia features}

Approximately $50 \%$ of non-cachectic patients scored positively on cachexia features, such as fatigue, anorexia, reduced

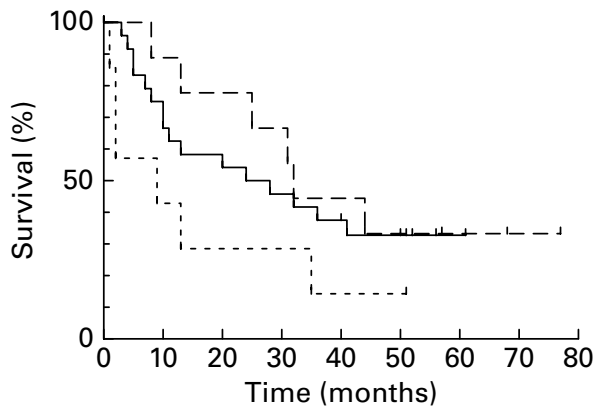

$\begin{array}{lcccccc}\text { No. of patients at risk } & 0 & 10 & 20 & 30 & 40 & 50 \\ \text { No cachexia: } & 24 & 18 & 14 & 11 & 9 & 7 \\ \text { Pre-cachexia: } & 9 & 8 & 7 & 6 & 4 & 3 \\ \text { Cachexia: } & 7 & 3 & 2 & 2 & 1 & 1\end{array}$

Fig. 1. Kaplan-Meier survival functions for no cachexia $(-; n 24)$, pre-cachexia $(-\llcorner; n$ ) and cachexia $(-.-$ - $n$ 7) in patients with stage III non-small-cell lung cancer, defined by the European Society for Parenteral and Enteral Nutrition Special Interest Group and cancer-specific framework of Fearon et al. ${ }^{(4,35)}$. $P=0.21$. handgrip strength and upper arm circumference, or increased CRP. In general, low percentages of patients scored positively on a reduced FFM index, albumin or $\mathrm{Hb}$ (Table 3 ).

For all instruments, groups with cachexia showed higher levels of CRP and IL- 6 and a lower $\mathrm{Hb}$ and serum albumin than patients with no cachexia $(P<0 \cdot 01)$ (Table 4). CRP was positively correlated with IL-6 $(r 0.55, P<0.01)$, and negatively correlated with $\mathrm{Hb}(r-0.47, P<0.01)$ and serum albumin $(r-0.71, P<0.01)$. The remaining inflammatory parameters were also significantly correlated with one another. Using different cut-off points for CRP ( $>5$ or $10 \mathrm{mg} / \mathrm{l}$ instead of $>8 \mathrm{mg} / \mathrm{l})$ did not change the presence of pre-cachexia and cachexia in individual patients (data not shown).

Of all patients, twelve (30\%) had a weight loss of at least $5 \%$ in the previous 12 months or less, three (8\%) had a FFM index below the 5 th percentile of reference values, twenty-seven (68\%) had decreased handgrip strength (below the lowest tertile of reference values), nineteen ( $48 \%$ ) experienced fatigue and twenty-three (58\%) experienced anorexia or reduced food intake. When comparing individual levels of inflammatory parameters with their reference values, CRP and serum IL-6 were elevated in, respectively, twenty-eight (70\%) and twenty (50\%) patients, and $\mathrm{Hb}$ and serum albumin were decreased in eight (20\%) and seven (18\%) patients, respectively (Table 3).

\section{Additional parameters}

REE per kg FFM, physical activity and phase angle were nonsignificantly different between groups. However, physical activity appeared to be lower in cachexia patients (Table 4).

\section{Discussion}

The purpose of the present explorative study was to study the presence of pre-cachexia and cachexia in patients with stage III NSCLC, by using consensus-based conceptual frameworks, which have not yet been applied or validated in populations of patients with cancer. Second, we explored the association of (pre)cachexia with survival and quality of life.

Although we are gaining knowledge on the pathophysiology and treatment of cancer cachexia, little is known about the typical profile and staging of cachexia. We chose to apply the only two available consensus-based frameworks to define cachexia. These frameworks were both comprehensive, but differed in the kind of parameters to define cachexia. The cut-off point of essential parameters, e.g. weight loss, is still a subject of debate. Therefore, we were interested in the outcomes of these two instruments when applied in a small, heterogeneous population of patients with locally advanced cancer.

These frameworks defined cachexia and described the clinical features associated with cachexia. More recently published proposals that aimed to grade the severity of cachexia led to the definition of pre-cachexia ${ }^{(1,4)}$. Using these proposals, it is possible to identify cancer patients with pre-cachexia: earlystage cachexia, characterised by moderate systemic inflammation and metabolic alterations, and minimal weight loss. 
Table 3. Number of patients with stage III non-small-cell lung cancer scoring on cachexia features according to the applied criteria*,†,ł (Number of participants and percentages)

\begin{tabular}{|c|c|c|c|c|c|c|c|c|c|c|c|c|}
\hline & & & \multicolumn{6}{|c|}{ Cancer } & \multicolumn{4}{|c|}{ Generalł } \\
\hline & \multicolumn{2}{|c|}{$\begin{array}{l}\text { Overall } \\
(n 40)\end{array}$} & \multicolumn{2}{|c|}{$\begin{array}{c}\text { No } \\
\text { cachexia } \\
(n 24)\end{array}$} & \multicolumn{2}{|c|}{$\begin{array}{l}\text { Pre-cachexia* } \\
\qquad(n 9)\end{array}$} & \multicolumn{2}{|c|}{$\begin{array}{l}\text { Cachexia } † \\
\quad(n 7)\end{array}$} & \multicolumn{2}{|c|}{$\begin{array}{c}\text { No } \\
\text { cachexia } \\
(n 29)\end{array}$} & \multicolumn{2}{|c|}{$\begin{array}{c}\text { Cachexia } \\
(n 11)\end{array}$} \\
\hline & $n$ & $\%$ & $n$ & $\%$ & $n$ & $\%$ & $n$ & $\%$ & $n$ & $\%$ & $n$ & $\%$ \\
\hline \multicolumn{13}{|l|}{ Weight loss/BMI } \\
\hline 0 to $\leq 5 \%(6 \text { months })^{*}$ & 19 & 48 & 19 & 79 & 9 & 100 & 0 & & 18 & 62 & 1 & 9 \\
\hline$>5 \%(6$ months $) \dagger$ & 12 & 30 & 5 & 21 & 0 & & 7 & 100 & 2 & 7 & 10 & 91 \\
\hline$>2 \%$ and $\mathrm{BMI}<20 \mathrm{~kg} / \mathrm{m}^{2} \dagger$ & 3 & 8 & 0 & & 0 & & 3 & 43 & 0 & & 3 & 27 \\
\hline$\geq 5 \%$ (12 months or less) $\ddagger$ & 12 & 30 & 5 & 21 & 0 & & 7 & 100 & 2 & 7 & 10 & 91 \\
\hline $\mathrm{BMI}<20 \mathrm{~kg} / \mathrm{m}^{2} \dagger$ & 4 & 10 & 1 & 4 & 0 & & 3 & 43 & 0 & & 4 & 36 \\
\hline \multicolumn{13}{|l|}{ FFM index } \\
\hline FFM index $<5$ th percentile (BIS) $\dagger$ & 3 & 8 & 1 & 4 & 1 & 11 & 1 & 14 & 1 & 3 & 2 & 18 \\
\hline FFM index $<10$ th percentile for age and sex (BIS) $\ddagger$ & 6 & 15 & 3 & 13 & 2 & 22 & 1 & 14 & 4 & 14 & 2 & 18 \\
\hline Upper arm circumference $<10$ th percentileł & 23 & 58 & 15 & 63 & 2 & 22 & 6 & 86 & 15 & 52 & 8 & 73 \\
\hline \multicolumn{13}{|l|}{ Muscle strength } \\
\hline Handgrip strength $<$ lowest tertile $\neq$ & 27 & 68 & 13 & 54 & 7 & 78 & 7 & 100 & 16 & 55 & 11 & 100 \\
\hline Fatigue (EORTC-QLQC30 question 18 , score 3 or 4 ) $\ddagger$ & 19 & 48 & 10 & 42 & 6 & 67 & 3 & 43 & 14 & 48 & 5 & 45 \\
\hline Anorexia/reduced food intake* $† \ddagger$ & 23 & 58 & 7 & 29 & 9 & 100 & 7 & 100 & 16 & 55 & 7 & 64 \\
\hline \multicolumn{13}{|l|}{ Inflammation } \\
\hline $\mathrm{Hb}<7.3 \mathrm{mmol} / \mathrm{l}$ & 8 & 20 & 3 & 13 & 1 & 11 & 4 & 57 & 3 & 10 & 5 & 45 \\
\hline $\mathrm{CRP}>5.0 \mathrm{mg} / \mathrm{l} \ddagger$ & 33 & 83 & 18 & 75 & 8 & 89 & 7 & 100 & 22 & 76 & 11 & 100 \\
\hline $\mathrm{CRP} \geq 8.0 \mathrm{mg} / \mathrm{l}^{*} \dagger$ & 28 & 70 & 13 & 54 & 8 & 89 & 7 & 100 & 17 & 59 & 11 & 100 \\
\hline $\mathrm{IL}-6>4.0 \mathrm{pg} / \mathrm{ml}$ & 20 & 50 & 7 & 29 & 8 & 89 & 5 & 71 & 14 & 48 & 6 & 55 \\
\hline Albumin $<320 \mathrm{~g} / \ddagger$ & 8 & 20 & 1 & 4 & 2 & 22 & 4 & 57 & 2 & 7 & 5 & 45 \\
\hline
\end{tabular}

FFM, fat-free mass; BIS, bioimpedance spectroscopy; EORTC-QLQC30, European Organisation for Research and Treatment of Cancer - Quality of Life Questionnaire C30; CRP, C-reactive protein.

*Cancer-specific framework for pre-cachexia.

† Cancer-specific framework for cachexia.

$\ddagger$ General framework for cachexia.

Patients with pre-cachexia are not always recognised by clinicians or nutritional screening instruments, while nutritional support is expected to prevent progressive loss of body weight and FFM. On the contrary, treatment options for cachexia are limited.

In the present population of patients at diagnosis of stage III NSCLC, pre-cachexia was prevalent in $23 \%$, but only the framework proposed by the ESPEN Special Interest Group ${ }^{(1)}$ defines pre-cachexia, while the general framework of Evans et al. ${ }^{(5)}$

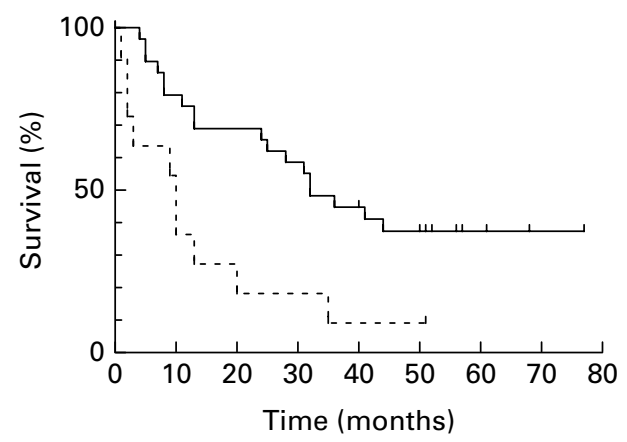

$\begin{array}{lcccccc}\text { No.of patients at risk } & 0 & 10 & 20 & 30 & 40 & 50 \\ \text { No cachexia: } & 29 & 23 & 20 & 17 & 13 & 10 \\ \text { Cachexia: } & 11 & 6 & 3 & 2 & 1 & 1\end{array}$

Fig. 2. Kaplan-Meier survival functions for no cachexia $(-; n$ 29) and cachexia $\left(--_{-} ; n\right.$ 11) in patients with stage III non-small-cell lung cancer, defined by the non-disease-specific, general framework of Evans et al. ${ }^{(5)}$. $P<0.01$. only defines cachexia. Cachexia was also prevalent in the present population, but the cancer-specific framework and the general framework for cachexia found a different number of patients with cachexia (respectively, 18 and $28 \%$ by the cancer-specific and non-disease-specific general framework).

A number of studies showed the association between survival and weight loss in general cancer populations ${ }^{(10,14,35)}$ and in patients with gastrointestinal ${ }^{(36)}$ and lung cancer ${ }^{(9)}$. One of the first papers on this topic found the combination of weight loss, food intake and systemic inflammation to be related to poor outcome in pancreatic cancer patients ${ }^{(35)}$. Because the definition of cachexia includes the presence of severe weight loss, the association with survival in the present study is consistent with these findings. The difficulty is that, in the literature, weight loss and cachexia are used disorderly, and that it is not possible to isolate starvation from cancer cachexia. Another component of the cachexia definition is inflammation. Systemic inflammation, amongst others reflected by elevated CRP and hypoalbuminaemia, is also negatively associated with survival ${ }^{(37,38)}$.

After carrying out baseline measurements at diagnosis, patients received different anticancer treatments and participated in a placebo-controlled randomised controlled trail comparing oral nutritional supplements containing $n-3$ PUFA with an isoenergetic placebo. Yet, the percentages of patients with (pre)cachexia and survival did not significantly differ among groups with different cancer treatments (data not shown). Preclinical studies suggest that an increased intake of $n$-3 PUFA decreases the risk of cancer development and 
Table 4. Differences in biochemistry, phase angle, resting energy expenditure (REE), physical activity and quality of life between cachexia groups with stage III non-small-cell lung cancer

(Mean values and standard deviations)

\begin{tabular}{|c|c|c|c|c|c|c|c|c|c|c|c|c|}
\hline & \multicolumn{7}{|c|}{ Cancer } & \multicolumn{5}{|c|}{ General } \\
\hline & \multicolumn{2}{|c|}{$\begin{array}{l}\text { No cachexia } \\
\quad(n \text { 24) }\end{array}$} & \multicolumn{2}{|c|}{$\begin{array}{l}\text { Pre-cachexia } \\
\qquad(n 9)\end{array}$} & \multicolumn{2}{|c|}{$\begin{array}{c}\text { Cachexia } \\
(n 7)\end{array}$} & \multirow[b]{2}{*}{$P^{\star}$} & \multicolumn{2}{|c|}{$\begin{array}{l}\text { No cachexia } \\
\quad(n 29)\end{array}$} & \multicolumn{2}{|c|}{$\begin{array}{l}\text { Cachexia } \\
(n 11)\end{array}$} & \multirow[b]{2}{*}{$P \dagger$} \\
\hline & Mean & SD & Mean & SD & Mean & SD & & Mean & SD & Mean & SD & \\
\hline $\mathrm{Hb}(\mathrm{g} / \mathrm{l})$ & 133 & 13 & 136 & 15 & 113 & 25 & 0.01 & 135 & 13 & 117 & 21 & 0.02 \\
\hline Serum albumin $(\mathrm{g} / \mathrm{l})$ & 383 & 38 & 371 & 40 & 320 & 64 & 0.01 & 384 & 31 & 328 & 62 & 0.01 \\
\hline CRP (mg/l) & 30.4 & $53 \cdot 6$ & $40 \cdot 1$ & 33.8 & $92 \cdot 0$ & $57 \cdot 0$ & 0.03 & $22 \cdot 3$ & $25 \cdot 2$ & $96 \cdot 5$ & 71.9 & 0.01 \\
\hline Serum IL-6 (pg/ml) & 3.2 & 2.5 & 7.3 & $3 \cdot 1$ & 14.9 & $12 \cdot 2$ & $<0.001$ & 4.6 & 3.3 & $11 \cdot 3$ & 11.6 & 0.10 \\
\hline Phase angle $\left({ }^{\circ}\right)$ & $6 \cdot 9$ & $2 \cdot 2$ & $6 \cdot 2$ & 0.6 & $6 \cdot 3$ & 0.7 & 0.55 & 6.8 & $2 \cdot 0$ & $6 \cdot 2$ & 0.6 & 0.33 \\
\hline REE $(k J) \ddagger$ & 6406 & 895 & 6623 & 950 & 5845 & 527 & 0.19 & 6510 & 937 & 5954 & 519 & 0.02 \\
\hline REE (kJ/kg FFM)‡ & 129 & 24 & 137 & 22 & 140 & 15 & 0.50 & 130 & 24 & 139 & 16 & 0.29 \\
\hline \multicolumn{13}{|l|}{ Physical activity } \\
\hline Day score (PAM activity score) & $6 \cdot 7$ & $5 \cdot 3$ & 5.5 & $2 \cdot 8$ & 4.3 & $2 \cdot 1$ & 0.57 & $6 \cdot 7$ & $5 \cdot 0$ & $4 \cdot 1$ & 1.8 & 0.19 \\
\hline Low-intensity physical activity (min/d) & $46 \cdot 5$ & 23.5 & $50 \cdot 8$ & $37 \cdot 2$ & $26 \cdot 4$ & $11 \cdot 0$ & 0.24 & 47.5 & $26 \cdot 4$ & 32.5 & $20 \cdot 0$ & 0.19 \\
\hline Moderate-intensity physical activity $(\mathrm{min} / \mathrm{d})$ & $32 \cdot 0$ & $21 \cdot 0$ & $28 \cdot 2$ & $17 \cdot 4$ & $25 \cdot 7$ & $20 \cdot 6$ & 0.81 & $32 \cdot 2$ & 20.5 & $24 \cdot 0$ & 17.5 & 0.36 \\
\hline \multicolumn{13}{|l|}{ EORTC-QLQC30 } \\
\hline Quality of life & $62 \cdot 3$ & $20 \cdot 7$ & $56 \cdot 5$ & $21 \cdot 6$ & 34.7 & $22 \cdot 6$ & 0.03 & $60 \cdot 4$ & $21 \cdot 6$ & $45 \cdot 8$ & $24 \cdot 0$ & 0.08 \\
\hline Physical functioning & $75 \cdot 7$ & $19 \cdot 8$ & 68.9 & $21 \cdot 3$ & $63 \cdot 6$ & 23.9 & 0.37 & $75 \cdot 0$ & $19 \cdot 3$ & $64 \cdot 1$ & 23.5 & 0.14 \\
\hline Role functioning & $59 \cdot 4$ & 34.8 & $40 \cdot 7$ & $29 \cdot 0$ & $41 \cdot 7$ & $41 \cdot 8$ & 0.29 & $53 \cdot 6$ & $32 \cdot 2$ & $48 \cdot 3$ & 43.4 & 0.73 \\
\hline Emotional functioning & $62 \cdot 0$ & $25 \cdot 0$ & 73.1 & 23.9 & $60 \cdot 7$ & $20 \cdot 8$ & 0.46 & $63 \cdot 7$ & $25 \cdot 6$ & 65.9 & $20 \cdot 2$ & 0.80 \\
\hline Cognitive functioning & 72.5 & $26 \cdot 9$ & 81.5 & $15 \cdot 5$ & $76 \cdot 2$ & $23 \cdot 3$ & 0.64 & $73 \cdot 2$ & $25 \cdot 0$ & $80 \cdot 3$ & $20 \cdot 8$ & 0.41 \\
\hline Social functioning & 65.9 & 31.6 & $64 \cdot 8$ & 29.4 & 44.4 & 40.4 & 0.35 & 64.9 & 29.9 & $55 \cdot 0$ & 40.1 & 0.42 \\
\hline
\end{tabular}

CRP, C-reactive protein; FFM, fat-free mass; PAM, Physical Activity Monitor; EORTC-QLQC30, European Organisation for Research and Treatment of Cancer - Quality of Life Questionnaire C30.

*ANOVA (comparing no-cachexia, pre-cachexia and cachexia groups).

$\dagger$ Independent samples $t$ test for equality of means (comparing no-cachexia and cachexia groups).

$\ddagger 1 \mathrm{~kJ}=0.239 \mathrm{kcal}$

progression. A few clinical studies support the potential benefit of $n-3$ PUFA on chemotherapy efficacy ${ }^{(39)}$ or cancer cell proliferation ${ }^{(40)}$. In the present population, patients who received oral nutritional supplements containing $n-3$ PUFA did not show a significantly different presence of cachexia or survival than control patients (data not shown).

On average, the present population of patients with stage III NSCLC showed a moderate amount of weight loss (on average $1.9 \%$ of pre-illness weight) during the previous 6 months and, consequently, a low prevalence of malnutrition (20\%). Other studies in patients with lung cancer (all types and stages) reported high percentages of malnutrition, i.e. $15 \cdot 6^{(7)}, 30^{(41)}$, $36^{(10)}$ and $50-61 \%{ }^{(11)}$. A study by Bozzetti \& Mariani ${ }^{(6)}$ showed an average weight loss of $9.5 \%$ in outpatients with lung cancer. Consequently, the percentage of patients with cachexia in the present patient population was relatively low ( $18 \%$ by the cancer-specific framework and $28 \%$ by the general definition). This could be explained by the selection of stage III NSCLC. As this is one of the first studies to assess pre-cachexia in stage III lung cancer, it is hard to compare these findings with other data. Op den Kamp et al. ${ }^{(42)}$ found a comparable amount of weight loss (average $3.1 \%$ ) in a group of sixteen newly diagnosed patients with stage I to III NSCLC. Compared with healthy controls, these patients also showed systemic inflammation, but no apparent loss of FFM. However, the present exploratory study did not describe pre-cachexia features (such as inflammation and anorexia) in individual patients ${ }^{(42)}$.

Weight loss was associated with an elevated $\operatorname{REE}^{(12,41)}$, systemic inflammatory response $\mathrm{e}^{(12,41)}$ and a reduced dietary intake $^{(41)}$ in patients with SCLC and NSCLC. Metabolic and inflammatory derangements seemed to be mainly related to the tumour; after resection ${ }^{(43)}$ or chemotherapeutic treatment ${ }^{(44)}$, REE in patients with lung cancer decreased. We did not find differences for REE per kg FFM between cachexia groups, probably due to high CRP and inflammation in the majority of patients. When uncorrected for FFM, REE in patients with cachexia (defined by the general framework for cachexia) was significantly lower, but this could be explained by the lower body weight in patients with cachexia. Because we used bioelectrical impedance spectroscopy to assess FFM (and not the 'gold standard' dual-energy X-ray absorptiometry), this may have resulted in over-estimation or under-estimation of FFM.

We also showed that approximately $50 \%$ of non-cachectic patients scored positively on cachexia features, such as moderate weight loss, systemic inflammation, fatigue, anorexia, reduced handgrip strength and upper arm circumference. The frameworks that we used define patients as pre-cachectic or cachectic when they experience a combination of cachexia features, inflammation and weight loss, which is consistent with the existing knowledge on the pathophysiology of cachexia. Other cachexia frameworks, e.g. the proposal of the SCReening the Nutritional Status in Oncology (SCRINIO) working group ${ }^{(6)}$ and the cachexia score ${ }^{(8)}$, were not consensus-based and therefore not selected to address the present research question.

A secondary aim of the present study was to explore quality of life and physical activity, and their association with cachexia. Overall, the present small sample size resulted in a low statistical power, which made it hard to demonstrate significant associations. Pre-cachexia and cachexia were associated with a reduced overall quality of life, but not with other quality 
of life parameters, such as physical function. In the literature, an association among nutritional status, inflammation and well-being in lung cancer has been described, but these studies did not assess cachexia in the way we $\operatorname{did}^{(45,46)}$.

Physical activity is an important indicator of quality of life and performance status in cancer patients ${ }^{(47)}$, and found to be reduced in patients with SCLC $^{(48)}$ and pancreatic cancer ${ }^{(24)}$. The present patients with stage III NSCLC also showed a lower physical activity than healthy subjects (approximately 6 v. 20) ${ }^{(33)}$, and patients with pre-cachexia and cachexia showed a non-significant lower physical activity than no-cachexia patients.

When using the selected frameworks, we encountered some issues. First, patients with weight loss as well as complaints and/ or inflammation were incorrectly justified as having no cachexia by the general framework, which requires three positive scores on complaints and inflammation. Patients with $\geq 5 \%$ weight loss, in combination with two positive scores on complaints and inflammation, were not classified as cachectic. Also, the ESPEN Special Interest Group did not classify these patients as pre-cachectic, as their weight loss was more than $5 \%$. Second, cut-off points for anorexia, CRP and FFM index were lacking for the pre-cachexia and cancer-specific frameworks. For precachexia, weight loss $\leq 5 \%$ was described, but it was unclear if this accounted for patients with a weight loss of $0 \%$. We solved these issues by consulting the authors. In line with current knowledge, we found a positive correlation between pro-inflammatory indexes (CRP and serum IL-6), and these were negatively correlated with $\mathrm{Hb}$ and serum albumin. Interestingly, when other cut-off points for inflammatory parameters were applied, we observed the same presence of (pre)cachexia.

Validation of cachexia instruments in large groups of patients with cancer is still required, but a 'gold standard' is lacking. The association of cachexia with survival is informative, but validation of instruments against one or more indicators of cachexia (e.g. standardised assessment of muscle mass) is preferable. Further studies in larger populations are warranted to validate these new instruments and to more extensively explore the prognostic value in patients with cancer. Ideally, worldwide cancer centres record a number of biomarkers and cachexia parameters, follow-up treatment adherence and survival, and merge these data in order to validate definitions and their prognostic value. A promising parameter might be proteolysis-inducing factor, which has been found in the urine of cachectic patients with cancer ${ }^{(49)}$.

In conclusion, new consensus-based frameworks show that pre-cachexia and cachexia are prevalent in patients with stage III NSCLC. Cachexia appears to be associated with a shorter overall survival and a reduced quality of life.

\section{Supplementary material}

To view supplementary material for this article, please visit http://dx.doi.org/10.1017/S0007114512004527

\section{Acknowledgements}

We would like to thank N. Kok (Department of Pulmonary Diseases, VU University Medical Center, Amsterdam,
The Netherlands) and V. van Adrichem (Department of Nutrition and Dietetics, VU University Medical Center, Amsterdam, The Netherlands) for their assistance with patient inclusion. Conflict of interest statement: B. S. v. d. M., J. A. L. and P. A. v. L. were funded by Abbott Nutrition. Abbott Nutrition provided funding for data collection, but was not involved in protocol development, data analysis or manuscript writing. C. P. S., M. M. and E. F. S. do not declare any conflicts of interest. B. S. v. d. M. conceived the study, participated in the design and coordination of the study, performed statistical analysis and drafted the manuscript. J. A. L. conceived the study, participated in the design and coordination of the study and helped to draft the manuscript. C. P. S. performed statistical analysis and helped to draft the manuscript. M. M. helped to interpret the data and to draft the manuscript. E. F. S. conceived of the study and helped to draft the manuscript. P. A. v. L. conceived of the study, participated in the design and coordination of the study and helped to draft the manuscript. The present work was presented as a poster at ESPEN, Goteborg, 2011.

\section{References}

1. Muscaritoli M, Anker SD, Argiles J, et al. (2010) Consensus definition of sarcopenia, cachexia and pre-cachexia: joint document elaborated by Special Interest Groups (SIG) "cachexia-anorexia in chronic wasting diseases" and "nutrition in geriatrics". Clin Nutr 29, 154-159.

2. Van Cutsem E \& Arends J (2005) The causes and consequences of cancer-associated malnutrition. Eur J Oncol Nurs 9, S51-S63.

3. Davis MP \& Dickerson D (2000) Cachexia and anorexia: cancer's covert killer. Support Care Cancer 8, 180-187.

4. Fearon K, Strasser F, Anker SD, et al. (2011) Definition and classification of cancer cachexia: an international consensus. Lancet Oncol 12, 489-495.

5. Evans WJ, Morley JE, Argiles J, et al. (2008) Cachexia: a new definition. Clin Nutr 27, 793-799.

6. Bozzetti F \& Mariani L (2009) Defining and classifying cancer cachexia: a proposal by the SCRINIO Working Group. JPENJ Parenter Enteral Nutr 33, 361-367.

7. Fox KM, Brooks JM, Gandra SR, et al. (2009) Estimation of cachexia among cancer patients based on four definitions. J Oncol 2009, 693458

8. Argiles JM, Lopez-Soriano FJ, Toledo M, et al. (2011) The cachexia score (CASCO): a new tool for staging cachectic cancer patients. J Cachex Sarcopenia Muscle 2, 87-93.

9. Ross PJ, Ashley S, Norton A, et al. (2004) Do patients with weight loss have a worse outcome when undergoing chemotherapy for lung cancers? Br J Cancer 90, 1905-1911.

10. Dewys WD, Begg C, Lavin PT, et al. (1980) Prognostic effect of weight loss prior to chemotherapy in cancer patients. Eastern Cooperative Oncology Group. Am J Med 69, 491-497.

11. Laviano A \& Meguid MM (1996) Nutritional issues in cancer management. Nutrition 12, 358-371.

12. Simons JP, Schols AM, Buurman WA, et al. (1999) Weight loss and low body cell mass in males with lung cancer: relationship with systemic inflammation, acute-phase response, resting energy expenditure, and catabolic and anabolic hormones. Clin Sci (Lond) 97, 215-223.

13. Staal-van den Brekel AJ, Dentener MA, Schols AM, et al. (1995) Increased resting energy expenditure and weight loss are related to a systemic inflammatory response in lung cancer patients. J Clin Oncol 13, 2600-2605. 
14. Ovesen L, Hannibal J \& Mortensen EL (1993) The interrelationship of weight loss, dietary intake, and quality of life in ambulatory patients with cancer of the lung, breast, and ovary. Nutr Cancer 19, 159-167.

15. Mohan A, Singh P, Kumar S, et al. (2008) Effect of change in symptoms, respiratory status, nutritional profile and quality of life on response to treatment for advanced non-small cell lung cancer. Asian Pac J Cancer Prev 9, 557-562.

16. Martin F, Santolaria F, Batista N, et al. (1999) Cytokine levels (IL-6 and IFN-gamma), acute phase response and nutritional status as prognostic factors in lung cancer. Cytokine 11, $80-86$.

17. Meij van der BS, Langius JAE, Smit EF, et al. (2010) Oral nutritional supplements containing ( $n-3)$ polyunsaturated fatty acids affect the nutritional status of patients with stage III non-small cell lung cancer during multimodality treatment. J Nutr 140, 1774-1780.

18. Lukaski HC, Bolonchuk WW, Hall CB, et al. (1986) Validation of tetrapolar bioelectrical impedance method to assess human body composition. J Appl Physiol 60, 1327-1332

19. Houtkooper LB, Lohman TG, Going SB, et al. (1996) Why bioelectrical impedance analysis should be used for estimating adiposity. Am J Clin Nutr 64, 436S-448S.

20. Kyle UG, Genton L, Karsegard L, et al. (2001) Single prediction equation for bioelectrical impedance analysis in adults aged 20-94 years. Nutrition $\mathbf{1 7}, 248-253$.

21. Gupta D, Lammersfeld CA, Vashi PG, et al. (2009) Bioelectrical impedance phase angle in clinical practice: implications for prognosis in stage IIIB and IV non-small cell lung cancer. BMC Cancer 9, 37 .

22. Weir JB (1949) New methods for calculating metabolic rate with special reference to protein metabolism. I Physiol 109, $1-9$

23. Mansell PI \& Macdonald IA (1990) Reappraisal of the Weir equation for calculation of metabolic rate. Am J Physiol 258, R1347-R1354.

24. Moses AW, Slater C, Preston T, et al. (2004) Reduced total energy expenditure and physical activity in cachectic patients with pancreatic cancer can be modulated by an energy and protein dense oral supplement enriched with $n$-3 fatty acids. Br J Cancer 90, 996-1002.

25. Wilson MM, Thomas DR, Rubenstein LZ, et al. (2005) Appetite assessment: simple appetite questionnaire predicts weight loss in community-dwelling adults and nursing home residents. Am J Clin Nutr 82, 1074-1081.

26. Burtis CA, Ashwood ER \& Tietz NW (1994) Tietz Textbook of Clinical Chemistry, 2nd ed. Philadelphia: W.B. Saundersen Company.

27. Purich DL \& Allison RD (2000) Handbook of Biochemical Kinetics. San Diego: Academic Press.

28. Dati F, Johnson AM \& Whicher JT (2001) The existing interim consensus reference ranges and the future approach. Clin Chem Lab Med 39, 1134-1136.

29. Bohannon RW, Peolsson A, Massy-Westropp N, et al. (2006) Reference values for adult grip strength measured with a Jamar dynamometer: a descriptive meta-analysis. Physiotherapy 92, 11-15.

30. Yates JW, Chalmer B \& McKegney FP (1980) Evaluation of patients with advanced cancer using the Karnofsky performance status. Nat Rev Cancer 45, 2220-2224.

31. Karnofsky DA \& Burchenal JH (1949) Evaluation of chemotherapeutic agents. In The Clinical Evaluation of Chemotherapeutic Agents in Cancer, p. 196 [CM MacLeod, editor]. Columbia: Columbia University Press.

32. Slootmaker SM, Chinapaw MJ, Schuit AJ, et al. (2005) Promoting physical activity using an activity monitor and a tailored web-based advice: design of a randomized controlled trial [ISRCTN93896459]. BMC Public Health 5, 134.

33. Slootmaker SM, Chinapaw MJ, Schuit AJ, et al. (2009) Concurrent validity of the PAM accelerometer relative to the MTI Actigraph using oxygen consumption as a reference. Scand J Med Sci Sports 19, 36-43.

34. Schutz Y, Kyle UU \& Pichard C (2002) Fat-free mass index and fat mass index percentiles in Caucasians aged 18-98 y. Int J Obes Relat Metab Disord 26, 953-960.

35. Fearon KC, Voss AC \& Hustead DS (2006) Definition of cancer cachexia: effect of weight loss, reduced food intake, and systemic inflammation on functional status and prognosis. Am J Clin Nutr 83, 1345-1350.

36. Andreyev HJ, Norman AR, Oates J, et al. (1998) Why do patients with weight loss have a worse outcome when undergoing chemotherapy for gastrointestinal malignancies? Eur J Cancer 34, 503-509.

37. McMillan DC, Crozier JE, Canna K, et al. (2007) Evaluation of an inflammation-based prognostic score (GPS) in patients undergoing resection for colon and rectal cancer. Int J Colorectal Dis 22, 881-886.

38. Jiang X, Hiki N, Nunobe S, et al. (2012) Prognostic importance of the inflammation-based Glasgow prognostic score in patients with gastric cancer. BrJ Cancer 107, 275-279.

39. Murphy RA, Mourtzakis M, Chu QS, et al. (2011) Supplementation with fish oil increases first-line chemotherapy efficacy in patients with advanced nonsmall cell lung cancer. Nat Rev Cancer 117, 3774-3780.

40. Aronson WJ, Kobayashi N, Barnard RJ, et al. (2011) Phase II prospective randomized trial of a low-fat diet with fish oil supplementation in men undergoing radical prostatectomy. Cancer Prev Res (Phila) 4, 2062-2071.

41. Staal-van den Brekel AJ, Schols AMWJ, ten Velde GPM, et al. (1994) Analysis of the energy balance in lung cancer patients. Cancer Res 54, 6430-6433.

42. Op den Kamp CM, Langen RC, Minnaard R, et al. (2012) Precachexia in patients with stages I-III non-small cell lung cancer: Systemic inflammation and functional impairment without activation of skeletal muscle ubiquitin proteasome system. Lung Cancer 76, 112-117.

43. Fredrix EW, Soeters PB, Wouters EF, et al. (1991) Effect of different tumor types on resting energy expenditure. Cancer Res 15, 6138-6141.

44. Staal-van den Brekel AJ, Schols AM, Dentener MA, et al. (1997) The effects of treatment with chemotherapy on energy metabolism and inflammatory mediators in smallcell lung carcinoma. Br J Cancer 76, 1630-1635.

45. Giannousi Z, Gioulbasanis I, Pallis AG, et al. (2012) Nutritional status, acute phase response and depression in metastatic lung cancer patients: correlations and association prognosis. Support Care Cancer 20, 1823-1829.

46. Gioulbasanis I, Georgoulias P, Vlachostergios PJ, et al. (2011) Mini Nutritional Assessment (MNA) and biochemical markers of cachexia in metastatic lung cancer patients: interrelations and associations with prognosis. Lung Cancer 74, 516-520.

47. Coups EJ, Park BJ, Feinstein MB, et al. (2009) Physical activity among lung cancer survivors: changes across the cancer trajectory and associations with quality of life. Cancer Epidemiol Biomarkers Prev 18, 664-672.

48. Gibney E, Elia M, Jebb SA, et al. (1997) Total energy expenditure in patients with small-cell lung cancer: results of a validated study using the bicarbonate-urea method. Metabolism 46, 1412-1417.

49. Tisdale MJ (2008) Catabolic mediators of cancer cachexia Curr Opin Support Palliat Care 2, 256-261. 